\title{
Impact of paternal age on intracytoplasmic sperm injection cycle results
}

\author{
Tuğçe Temel ${ }^{1}$, Yaşam Kemal Akpak², İsmet Gün ${ }^{3}$, Serkan Oral ${ }^{4}$, Kenan Sofuoğlu ${ }^{1}$
}

\author{
${ }^{1}$ Reproductive Medicine and IVF Unit, Zeynep Kamil Women's and Children's Hospital, Istanbul, Turkey \\ ${ }^{2}$ Department of Obstetrics \& Gynaecology, Ankara Mevki Military Hospital, Ankara, Turkey \\ ${ }^{3}$ Department of Obstetrics \& Gynaecology, GATA Haydarpaşa Training Hospital, Istanbul, Turkey \\ ${ }^{4}$ Department of Assisted Reproduction, LIV Hospital, Istanbul, Turkey
}

Received: 05 March 2015

Accepted: 19 April 2015

\section{*Correspondence:}

Dr. Tuğçe Temel,

E-mail: colak_451@hotmail.com

Copyright: ( ) the author(s), publisher and licensee Medip Academy. This is an open-access article distributed under the terms of the Creative Commons Attribution Non-Commercial License, which permits unrestricted non-commercial use, distribution, and reproduction in any medium, provided the original work is properly cited.

\begin{abstract}
Background: The purpose of this study is to compare the impacts of the paternal age of patients included in the intracytoplasmic sperm injection-embryo transfer cycle administered with long protocol.

Methods: The patients administered with long agonist protocol, who were primary infertile and had normal over reserves, were divided into two groups based on their sperm concentration. The patients with sperm concentration of over $15 \mathrm{million} / \mathrm{ml}$ were defined as group 1, while those with sperm concentration below $15 \mathrm{million} / \mathrm{ml}$ were defined as group 2.

Results: 602 patients, 302 of whom were in group 1 and 300 of whom were in group 2, enrolled in this study. With regard to treatment results, the implantation rates and clinical pregnancy rates were significantly higher in group 1 . In an assessment made to determine if the advanced male age had any impact on the clinical pregnancy rates, it was determined that there was a significant decrease in the clinical pregnancy rates only in group 2 . When the patients in group 2 were divided and compared into two patient subgroups, i.e. those below 37 years old and over 37 years old, higher number of mature oocytes, embryos was obtained at a lower dose of recombinant follicular stimulant hormone $(\mathrm{r}-\mathrm{FSH})$ in the younger patient subgroup, which significantly increased the clinical pregnancy rates with implementation rates.

Conclusions: While the pregnancy and implantation rates significantly decreased by advanced paternal age in
\end{abstract} oligospermic patients administered with ICSI, the abortus rates increased.

Keywords: Paternal factor, Infertility, Oligospermia, In vitro fertilization, Male factor, Intracytoplasmic sperm injection

\section{INTRODUCTION}

Almost $15 \%$ of the couples are infertile globally and the reason of approximately half of the cases is male factor. ${ }^{1}$ In the capital world, most of the couples marry in advanced ages due to concern for the future, occupational and academic career and have babies in advanced ages. Both women and men face with infertility problems associated with advanced age. In a study, which investigated the semen samples of males over 45 years old, a significant decrease was observed in the semen volume, sperm mobility and sperm morphology. ${ }^{2}$ However, in another study, it was found that the sperm concentration did not change by age on the contrary of the other sperm parameters. ${ }^{2}$ Although such data demonstrate that spermatogenesis decrease in older men compared to younger men, this decrease raises a concern in terms of fertility performance. ${ }^{2-5}$ Some studies also reported that testis morphology and semen production can be completely normal in older men or the negative 
impacts may not be at the same magnitude in all men. ${ }^{6,7}$ There are a few studies investigating the impacts of the fertility of older men independently from the women infertility. ${ }^{8,9}$

Also it was considered that the increase in some genetic diseases might be associated with the paternal age, the extent of its impact on structural and numerical chromosomal anomalies is not clear. ${ }^{6,10}$ No significant difference in chromosomal anomaly was found between advanced age male and young men in a study, which included screening of anomaly on autosomal chromosomes no. 9 and 18 and sex hormones in sperm samples. ${ }^{11}$ On the contrary of this study, another study showed that the incidence of non-separation of paternal sex hormones in meiosis I was higher in older men with idiopathic infertility and that the risk of observing XXY fetus was higher in males over 39 years old, who had idiopathic infertility. ${ }^{12}$

The purpose of this study is to retrospectively compare the impacts of the paternal age of patients included in the intracytoplasmic sperm injection-embryo transfer (ICSIET) cycle administered with long protocol on highquality embryo rates, implantation rates, pregnancy losses and successful pregnancy results and to determine if it has any negative impacts.

\section{METHODS}

Approval of the ethical committee was obtained from the ethical committee of the hospital, which planned and performed the study, prior to commencement of the study. This study was performed on the files of patients admitted to Zeynep Kamil Women's and Children's Hospital, Reproductive Medicine and IVF Unit between 01.01.2009 and 31.07.2013.

The patients, who were primary infertile, administered with long agonist protocol, between 23 and 35 years old (20-50 years old for men), had Body Mass Index (BMI) of $18-28 \mathrm{~m} 2 / \mathrm{kg}$ and normal over reserve, enrolled in this study. The patients, who were asospermic, secondary infertile, had decreased over reserve (basal FSH $\geq 10$ $\mathrm{mIU} / \mathrm{ml}$, basal estradiol (E2) $>80 \mathrm{pg} / \mathrm{ml}$ and number of antral follicles $\leq 6$ ), systemic and endocrinologic disease, uterine and/or ovarian pathology (such as endometrioma, endometrial polype, submucous myoma and uterine septum), previous uterine and/or over surgical history, were unable to undergo frozen embryo application, cycle cancellation or ET and developed ovarian hyperstimulation syndrome (OHSS), were excluded from this study.

The patients, who were eligible for these study criteria, were divided into to groups by sperm concentration. The patients with sperm concentration of over 15 million $/ \mathrm{ml}$ were defined as group 1 (normospermic), while those with sperm concentration below $15 \mathrm{million} / \mathrm{ml}$ were defined as group 2 (oligospermic). Semen samples are collected by masturbation into a sterile container after 3-5 days of ejaculatory abstinence. Liquefaction takes $30 \mathrm{~min}$ at room temperature. The results of each spermiogramme analysis were obtained by examining the semen using Makler sperm count camera according to WHO criteria at least two times. ${ }^{13}$ The demographical characteristics, over reserve results, sperm parameters, treatment doses and results of the patients in both groups were recorded in the patent files and then compared. The parameters associated with male age and the correlation coefficient between them were determined.

GnRH agonist was started on day 21 of the previous cycle in long protocol. If the patient became menses, the patient was called for TV-USG and basal hormone control on day 2 or two weeks later, if the patient did not become menses. If the level of E2 was below $30 \mathrm{pg} / \mathrm{ml}$ and the endometrial thickness in USG was below $6 \mathrm{~mm}$, gonadotropin treatment was started a day later, i.e. on day 3 of the cycle if menses occurred. r-FSH [(Puregon; Organon, Netherland or Gonal-F; Serono, Italy] was administered in ovarian stimulation. The baseline dose was personalized based on the experiences on basal hormone values, basal ultrasound results, age, BMI and previously controlled ovarian hyperstimulation. The number and size of follicles and serum estradiol were measured with USG as of day 5 of stimulation. Dose was adjusted accordingly. GE Medical (Logic alpha $200 \mathrm{GE}$ Medical A/S Milwaukee, USA) ultrasound device was used in the ultrasound imaging. Stimulation was continued until date of hCG. When the leading follicle became $18 \mathrm{~mm}$ or at least three of the follicles became 17 $\mathrm{mm}$, ovulation was triggered with urinary hCG $10000 \mathrm{IU}$ (Pregnyl amp, Organon, Turkey) or r-hCG $250 \mu \mathrm{gr}$ (Ovitrelle, Serono, Italy). Oocytes were collected 35-36 hours after application of hCG. All follicles of $14 \mathrm{~mm}$ and over were aspirated during oocyte collection process. The oocytes after retrieval are incubated in culture medium at $37 \mathrm{C}$ for $18 \mathrm{~h}$. The fertilization and embryo quality were assessed under microscope at hours 20, 48 and 72 by an expert embryologist. During assessment of embryo quality, the cell count and 5 parameters defining the embryo morphology were used (fragmentation extent, location of fragmentations, similarity of blastomeres, multinucleation, and cytoplasmic appearance). The embryos with the highest quality (grade 1) were defined as those with 4-5 cells on day 2 or 7 cells on day 3 as well as the embryos with fragmentation below $20 \%$ occurred in the blastomers with equal sizes and with no multinucleation. One of the embryos preferably with grade 1 good quality, scored 2-3 days after collection of oocytes according to ICSI standard procedure, was transferred to the uterine cavity. All patients were provided with luteal support using Crinone gel $8 \%$ (Progesterone 8\%, Serono, Italy) in the morning following collection of the oocytes. In case of pregnancy, the vaginal progesterone support were continued until week 12 of pregnancy. 
Positive serum beta-hCG following embryo transfer was considered as chemical pregnancy, monitoring intrauterine gestational sac with fetal heart beat with ultrasonography 5-6 weeks following transfer was considered as clinical pregnancy, presence of at least one alive fetus at the end of week 10-11 following transfer was considered as ongoing pregnancy. The ratio of highquality embryo was calculated by dividing the number of fertilized oocytes by the number of embryos. The implantation rate was calculated by dividing the number of gestational sac by the number of embryos transferred.

Mean, standard deviation, median, minimum and maximum rates and frequency were used in the complementary statistics of the data. The distribution of the variables was checked using Kolmogorov Simirnov test. Mann-whitney $U$ test was used for analysis of the quantitative data, while Chi square test was used in analysis of the qualitative data. The level of impact was analyzed using ROC curve. SPSS 21.0 software was used in analysis and $\mathrm{P}<0.05$ was used to determine significant values.

\section{RESULTS}

Mean age of the female patients enrolled in the study was $29.5 \pm 3.7$ years, while that of the male patients was 34.1 \pm 4.2 years. Of the patients included in ICSI cycle, 254 $(42.5 \%)$ were included with infertility, $46(7.7 \%)$ were included for tubal factor, $302(50.2 \%)$ were included for male factor. A total of 602 patients enrolled in the study, 302 of whom were included in group 1 and 300 of whom were included in group 2.

The mean age of women was higher in group 1, although it was not a clinically significant factor between the groups. With regard to treatment results, the implantation rates $(0.14 \pm 0.25$ and $0.09 \pm 0.20, \mathrm{P}=0.006)$ and clinical pregnancy rates were significantly higher in group 1 (38.7\% and $28.5 \%, \mathrm{P}=0.009)$ (Table 1$)$.

Table 1: Demographical and reproductive characteristics of groups.

\begin{tabular}{|c|c|c|c|c|c|}
\hline & \multicolumn{2}{|l|}{ Group 1} & \multicolumn{2}{|l|}{ Group 2} & \multirow{2}{*}{$\mathbf{P}$} \\
\hline & Mean \pm SD/n (\%) & Med (Min-Max) & Mean \pm SD/n (\%) & Med (Min-Max) & \\
\hline Female age (year) & $30.0 \pm 3.2$ & $31(22-35)$ & $28.9 \pm 4.1$ & $29(5-35)$ & 0.001 \\
\hline Male age (year) & $34.3 \pm 4.1$ & $35(26-47)$ & $33.9 \pm 4.3$ & $35(24-46)$ & 0.326 \\
\hline Infertility time (years) & $5.0 \pm 3.5$ & $4(1-19)$ & $5.0 \pm 3.1$ & $4(1-16)$ & 0.635 \\
\hline Semen volume $(\mathrm{ml})$ & $3.1 \pm 1.4$ & $3(0.7-7.5)$ & $2.7 \pm 1.4$ & $3(0.5-6.5)$ & 0.001 \\
\hline Semen conc. (mil.) & $66.8 \pm 35.0$ & $63(13-185)$ & $2.6 \pm 2.7$ & $2(0-10)$ & 0.000 \\
\hline Total motility (mil.) & $67.8 \pm 18.6$ & $73(0.5-94)$ & $44.8 \pm 24.0$ & $45(0.0-96)$ & 0.000 \\
\hline Slow moving (mil.) & $55.9 \pm 22.0$ & $63(3.0-89)$ & $34.8 \pm 23.2$ & $30(0.0-84)$ & 0.000 \\
\hline Fast moving (mil.) & $3.9 \pm 8.9$ & $0(55)$ & $0.5 \pm 2.7$ & $0(0.0-25)$ & 0.000 \\
\hline Immobile (mil.) & $31.9 \pm 17.5$ & $27(87)$ & $55.2 \pm 24.0$ & $55(4.0-100)$ & 0.000 \\
\hline Onsite moving (mil.) & $8.7 \pm 5.9$ & $7(0.0-30)$ & $9.5 \pm 7.8$ & $9(0.0-45)$ & 0.329 \\
\hline $\begin{array}{l}\text { Number of mature oocyte } \\
\text { (number) }\end{array}$ & $7.57 \pm 4.36$ & $7(1.0-20)$ & $7.44 \pm 4.02$ & $7(1.0-18.0)$ & 0.965 \\
\hline $\begin{array}{l}\text { Number of embryo } \\
\text { (number) }\end{array}$ & $4.07 \pm 2.65$ & $4(1.0-12)$ & $4.44 \pm 2.95$ & $4(1.0-16.0)$ & 0.111 \\
\hline Implantation rate & $0.14 \pm 0.25$ & $0(0.0-1)$ & $0.09 \pm 0.20$ & $0(0.0-1.0)$ & 0.006 \\
\hline $\begin{array}{l}\text { Rate of high-quality } \\
\text { embryos }\end{array}$ & $0.91 \pm 0.28$ & $1(0.0-1)$ & $0.95 \pm 0.23$ & $1(0.0-1.0)$ & 0.115 \\
\hline $\begin{array}{l}\text { Clinical pregnancy } \\
\text { (number/\%) }\end{array}$ & $116(38.7 \%)$ & & $85(28.5 \%)$ & & 0.009 \\
\hline Abortus (number/\%) & $20(17.4 \%)$ & & $18(21.4 \%)$ & & 0.474 \\
\hline
\end{tabular}

Chi-square test and Mann-Whitney U test were used to compare the non-parametric values

When a correlation test was performed for the parameters associated with the male age in both groups, no correlation was observed in group 1, while there was a negative correlation between age and male age in group and number of mobile sperms, number of high-quality embryos and implantation rates, which were sperm parameters, and a positive correlation between the infertility time and number of mature oocytes in group 2 (Table 2).

No significant impact of male age was observed on the clinical pregnancy rates in group 1 [E.A.A:0.471 (0.4030.539)] ( $\mathrm{P}>0.05)$. A significant impact of male age was observed on the clinical pregnancy rates in group 2 
[E.A.A:0.579 (0.510-0.648)] (P <0.05) (Figure 1). Age of 37 years was determined as the maximum cut-off value under curve in the oligospermic group according to ROC curve (Figure 1).

Table 2: Correlation of male age and other parameters in both groups.

\begin{tabular}{|c|c|c|c|c|c|c|c|c|c|c|c|c|c|}
\hline & & $\begin{array}{l}\text { Inf. } \\
\text { time }\end{array}$ & $\begin{array}{l}\text { Semen } \\
\text { volume }\end{array}$ & $\begin{array}{l}\text { Semen } \\
\text { conc. }\end{array}$ & $\begin{array}{l}\text { Total } \\
\text { motil. }\end{array}$ & $\begin{array}{l}\text { Slow } \\
\text { moving }\end{array}$ & $\begin{array}{l}\text { Fast } \\
\text { moving }\end{array}$ & Immobile & $\begin{array}{l}\text { Onsite } \\
\text { moving }\end{array}$ & $\begin{array}{l}\text { Mature } \\
\text { oocyte } \\
\text { nmber }\end{array}$ & $\begin{array}{l}\text { Embr. } \\
\text { number }\end{array}$ & $\begin{array}{l}\text { Imp. } \\
\text { Rate }\end{array}$ & $\begin{array}{l}\text { High } \\
\text { quality } \\
\text { embr. } \\
\text { rate }\end{array}$ \\
\hline \multirow{2}{*}{$\begin{array}{l}\text { Group } 1 \\
\text { (Male age) }\end{array}$} & $\mathrm{r}$ & -0.006 & -0.080 & -0.001 & -0.067 & -0.059 & 0.016 & 0.070 & 0.081 & 0.020 & -0.003 & 0.046 & 0.028 \\
\hline & $\mathrm{P}$ & 0.917 & 0.167 & 0.986 & 0.246 & 0.308 & 0.788 & 0.230 & 0.160 & 0.732 & 0.952 & 0.427 & 0.628 \\
\hline \multirow{2}{*}{$\begin{array}{l}\text { Group } 2 \\
\text { (Male age) }\end{array}$} & $\mathrm{r}$ & 0.184 & 0.048 & -0.003 & -0.068 & -0.029 & -0.128 & 0.040 & -0.041 & 0.166 & -0.125 & -0.125 & 0.060 \\
\hline & $\mathrm{P}$ & 0.001 & 0.414 & 0.954 & 0.243 & 0.613 & 0.027 & 0.486 & 0.481 & 0.004 & 0.031 & 0.031 & 0.304 \\
\hline
\end{tabular}

Spearman correlation test is used in this table

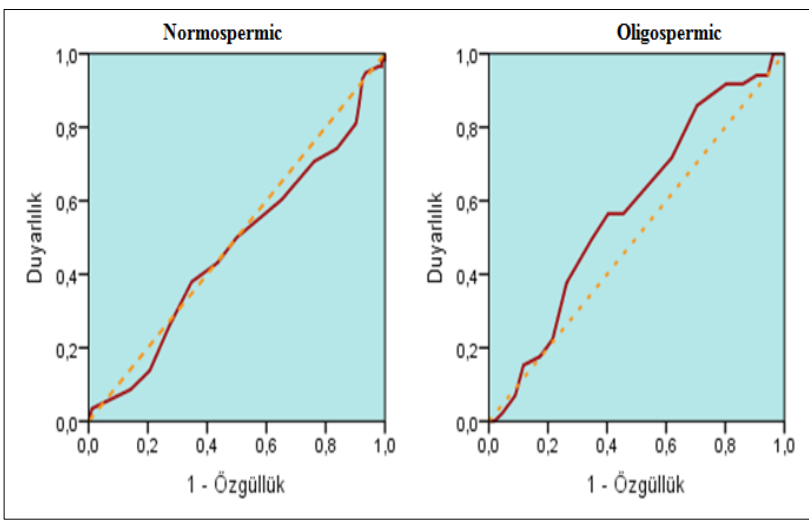

Figure 1: Assessment of positive clinical pregnancy and male age using ROC curve.
When two groups were compared considering the male age limit was 37 in the normospermic group, no statistically significant difference was determined in terms of all semen parameters, total r-FSH dose, number of mature oocytes, number of embryos, implantation rate, rate of high-quality embryos, rate of clinical pregnancy and abortus rate (Table 3).

While the number of mature oocytes, number of embryos, implantation rate and clinical pregnancy rate of couples with males below 37 years old was higher than that of the males over 37 years old in group 2, less r-FSH dose was used compared to this group. Although the abortus rates were not statistically significant, it was observed less in terms of percentage in couples with males below 37 years old (Table 4).

Table 3: Distribution of semen parameters and pregnancy results of group 1 patients.

\begin{tabular}{|c|c|c|c|c|c|}
\hline \multirow{2}{*}{ Group 1} & \multicolumn{2}{|c|}{ Male age below 37 years } & \multicolumn{2}{|c|}{ Male age below 37 years } & \multirow{2}{*}{$\mathbf{P}$} \\
\hline & Mean \pm SD/n (\%) & Med (Min-Max) & Mean \pm SD/n $(\%)$ & Med (Min-Max) & \\
\hline Infertility time (years) & $5.0 \pm 3.4$ & $4(1-19)$ & $5.4 \pm 3.3$ & $5(1-13)$ & 0.744 \\
\hline E2 level (pg/ml) & $49.6 \pm 19.6$ & $48(11-126)$ & $46.1 \pm 14.9$ & $44(11-78)$ & 0.518 \\
\hline Semen concentration (mil.) & $65.7 \pm 34.5$ & $62(13-177)$ & $70.1 \pm 36.4$ & $65(16-185)$ & 0.341 \\
\hline Total motility (mil.) & $67.7 \pm 19.6$ & $74(1-91)$ & $68.2 \pm 15.4$ & $71(33-94)$ & 0.380 \\
\hline Total r-FSH dose (IU) & $2945 \pm 1192$ & $3000(850-8400)$ & $2648 \pm 832$ & $2700(1075-4500)$ & 0.077 \\
\hline Number of mature oocyte (number) & $7.68 \pm 4.37$ & $7(1-20)$ & $7.28 \pm 4.33$ & $7(1-20)$ & 0.551 \\
\hline Number of embryo (number) & $4.16 \pm 2.70$ & $4(1-12)$ & $3.82 \pm 2.50$ & $3(1-10)$ & 0.379 \\
\hline Implantation rate & $0.13 \pm 0.23$ & $0(0-1)$ & $0.17 \pm 0.28$ & $0(0-1)$ & 0.216 \\
\hline Rate of high-quality embryos & $0.92 \pm 0.27$ & $1(0-1)$ & $0.90 \pm 0.31$ & $1(0-1)$ & 0.562 \\
\hline
\end{tabular}

Chi-square test and Mann-Whitney U test were used to compare the non-parametric values 
Table 4: Distribution of semen parameters and pregnancy results of group 2 patients.

\begin{tabular}{|llllll|}
\multirow{2}{*}{ Group 2 } & \multicolumn{2}{l}{ Male age below 37 years } & \multicolumn{2}{l|}{ Male age of 37 or over } & P \\
& Mean \pm SD/n $(\%)$ & Med (Min-Max) & Mean \pm SD/n $(\%)$ & Med (Min-Max) & 0.968 \\
\hline Infertility time (years) & $4.9 \pm 2.9$ & $4(1-16)$ & $5.2 \pm 3.7$ & $4(1-16)$ & 0.161 \\
\hline E2 level (pg/ml) & $48.8 \pm 16.6$ & $46(17-100)$ & $54.4 \pm 28.4$ & $46(27-198)$ & 0.627 \\
\hline Semen volume (ml) & $2.7 \pm 1.4$ & $3(0.5-6.5)$ & $2.7 \pm 1.5$ & $3(0.5-6.5)$ & 0.278 \\
\hline Semen concentration (mil.) & $2.7 \pm 2.7$ & $2(0-10)$ & $2.2 \pm 2.6$ & $2(0-10)$ & 0.819 \\
\hline Total motility (mil.) & $45.0 \pm 24.4$ & $45(0-96)$ & $44.4 \pm 23.0$ & $45(1-90)$ & 0.777 \\
\hline Slow moving (mil.) & $34.5 \pm 23.0$ & $30(0-84)$ & $35.6 \pm 24.2$ & $38(0-83)$ & 0.772 \\
\hline Onsite moving (mil.) & $9.8 \pm 8.4$ & $9(0-45)$ & $8.7 \pm 5.8$ & $9(0-23)$ & $\mathbf{0 . 0 0 2}$ \\
\hline Total r-FSH dose (IU) & $2509 \pm 1014$ & $2325(1150-6300)$ & $2791 \pm 844$ & $2750(1500-4500)$ & $\mathbf{0 . 0 0 3}$ \\
\hline Number of mature oocyte (number) & $7.71 \pm 3.68$ & $7(1-18)$ & $6.63 \pm 4.81$ & $5(1-18)$ & $\mathbf{0 . 0 0 8}$ \\
\hline Number of embryo (number) & $4.70 \pm 3.00$ & $4(1-16)$ & $3.65 \pm 2.65$ & $2(1-10)$ & $\mathbf{0 . 0 0 5}$ \\
\hline Implantation rate & $0.10 \pm 0.20$ & $0(0-1)$ & $0.06 \pm 0.19$ & $0(0-1)$ & 0.231 \\
\hline Rate of high-quality embryos & $0.94 \pm 0.24$ & $1(0-1)$ & $0.97 \pm 0.16$ & $1(0-1)$ & $\mathbf{0 . 0 0 5}$ \\
\hline Clinical pregnancy (number/\%) & $73(33 \%)$ & & $12(16 \%)$ & & 0.745 \\
\hline Abortus (number/\%) & $15(21 \%)$ & & $3(25 \%)$ & & \\
\hline
\end{tabular}

Chi-square test and Mann-Whitney U test were used to compare the non-parametric values

\section{DISCUSSION}

When especially the patient group below 37 years is compared to the patients group of 37 years or over in the patients with sperm count below 15 millions, higher number of mature oocytes, embryos is obtained at a lower dose of r-FSH in the younger patient subgroup, which significantly increases the clinical pregnancy rates with implementation rates. However, no significant difference was determined in the patient subgroup with sperm count over 15 millions.

Today, advanced paternal age has a negative impact on female fertility due to the decreased quantity and quality in the oocyte pool. ${ }^{14}$ With the increase in maternal age, the pregnancy rates, high-quality embryo rates and implantation rates decrease especially over 36 years old, while a significant increase is observed in trisomy and spontaneous abortus rates with normal karyotype. ${ }^{15-18}$ There are some recent studies investigating the impacts of the paternal age on pregnancy results. In a study performed by Paulson et al on 558 oocyte donors with 441 cases, the paternal age showed negative impacts only on the number of sperms, while no association was found between the pregnancy, fertilization and live birth rates. ${ }^{5}$ In contrary to this study, there are also some studies suggesting that the pregnancy ${ }^{19}$ and live birth rates will decrease $^{20}$ and abortus rates will increase ${ }^{21}$ by advanced paternal age.

While menopause occurs in women upon termination of ovarian functions, spermatogenesis continues for the entire life in men. ${ }^{22}$ In addition, some negative impacts occur in the reproductive organs and tissues by age. The testicular volume slowly decreases and serum sex steroid levels decrease towards decade $8 .{ }^{19}$ Although there are some publications suggesting that the advanced age has a negative impact on the semen parameters, ${ }^{23}$ there are also some studies suggesting that the semen parameters do not change by advanced age. ${ }^{24}$ Levitas et al. reported that there is a significant decrease in sperm concentration and total number of motile sperms especially after 55 years old in a study they performed with 6022 normospermic patients (respectively $24.3 \%$ and $53 \%$ ). ${ }^{25}$ Fisch et al. reported that there is a slow but significant decrease in the sperm concentration by age, but no change in the number of motile sperms and semen volume by age in a study they performed with 1283 normospermic and oligospermic patients. ${ }^{26}$ And, in our study, there is no significant correlation between the number of sperms, sperm concentration and total number of motile sperms and male age in group 1, while there is a negative correlation only with the number of fast moving sperms in the semen parameters in group 2.

And when paternal age is assessed in terms of fertility beyond the sperm parameters, a study with 221 patients taken to IVF cycle suggested that the paternal age decreased the success rate of achieving pregnancy by $5 \%$ when the other factors effecting the pregnancy results, such as maternal age and male semen parameters, are considered. ${ }^{20}$ In contrary to this finding, a study on age, which investigated 451 IVF cycles, showed that advanced male age did not have any negative impact on the successful IVF results. ${ }^{27}$

And in another study, the implantation rates $(29.3 \%$ below 35 years, $29.6 \%$ over 40 years) showed no significant change by advanced paternal age. ${ }^{4}$ In a study similar to our study, which investigated 1024 couples administered with ICSI, the pregnancy and implantation rates did not show a significant difference in the 
normospermic patient group, while a decrease of $5 \%$ in the pregnancy rates and a significant decrease in the implantation rate was determined by age in the oligospermic patient group. ${ }^{28}$ In our study, the pregnancy and implantation rates showed no statistically significant change in the patient group 1, while the pregnancy and implantation rates decreased significantly in group 2 .

It is unknown if the age has any impact on the pregnancy results in the normospermic patients. However, the decreased semen quality and genetic changes by age may be associated with the decrease in pregnancy and implantation rates in oligospermic patients. Spermatogenesis is a process that continues throughout the lifetime, but some errors are also observed in the spermatogenesis phases by age. ${ }^{19,29}$ Spandorfer et al. assessed 821 ICSI cycles in their study and found a increase in formation of digyny by paternal age in fertilization phase, but no difference in the bipronucleer fertilization. ${ }^{4}$ Again, no relation was observed between the pregnancy and implantation rates and paternal age in this study. And Ferreira et al found that paternal age has a negative impact on the implantation and pregnancy rates in oligospermic patients, while they reported no relation with age in both groups (normospermic and oligospermic) in the high-quality embryo rates. ${ }^{28}$ In our study, we found no relation between the paternal age and high-quality embryo rates in either group.

We found that trisomy was caused by paternal age only $9 \%$ of a series of 432 cases. ${ }^{30}$ Sartorelli et al. found that numeric and structural chromosome anomalies (acentric fragments and complex radial figures) significantly increased by advanced male age as a result of a comparison between males of 23-39 years old and males of 50-74 years old. ${ }^{31}$ However, no significant relation was found between the paternal age and abortus rates between two groups in a study, which compared the oligospermic and normospermic patient groups in terms of abortus rates. ${ }^{28}$ In a multicenter study, the patients were divided into 3 risk zones in terms of pregnancy loss and the highest risk was observed in a group with maternal age $>35$ and paternal rate $>40$ (OR: 2.87 ; 95\% CI: $1.86-$ $4.45) .{ }^{21}$ Ford et al. found that the upper limit for male age was 35 years in terms of the first trimester abortus risk. ${ }^{19}$ And in our study, we observed no increase in the abortus rate by paternal age in the patient group 1, while the pregnancy rates and implantation rates decreased significantly and abortus rates increased especially in patients over 37 years old in group 2. As the oldest patient was 47 years old and the mean age was 35 years old in the patient groups enrolled in our study, we believe that the upper age limit that has a negative impact on the pregnancy results was found to be lower compared to the other studies.

\section{CONCLUSION}

In the developing countries, the desire to have baby during advanced ages increases the number of patients applying to the polyclinics. It is known that age over 35 years is a significant risk factor in women. Thanks to the increasing number of studies that investigate the impacts of paternal age on pregnancy results, it is seen that paternal age is a factor that has a negative impact on especially implantation and abortus rates. In our study, the pregnancy rates and implantation rates decrease significantly and abortus rates increase in the patient group with sperm count below 15 millions.

The researchers strive to develop new methods to increase the success rate of ART (Assisted Reproductive Technologies). Age is not a recoverable factor, but the studies show that the male age is a reproductive risk factor in couples enrolled in ICSI cycles due to oligospermy.

\section{Funding: No funding sources \\ Conflict of interest: None declared}

Ethical approval: The study was approved by the local hospital ethics committee

\section{REFERENCES}

1. Barazani Y, Agarwal A, Sabanegh ES Jr. Functional sperm testing and the role of proteomics in the evaluation of male infertility. Urology. 2014;84:25561.

2. Hellstrom WJ, Overstreet JW, Sikka SC, Denne J, Ahuja S, Hoover AM, et al. Semen and sperm reference ranges for men 45 years of age and older. $\mathrm{J}$ Androl. 2006;27:421-8.

3. Hermann M, Untergasser G, Rumpold H, Berger P. Aging of the male reproductive system. Exp Gerontol. 2000;35:1276-9.

4. Spandorfer SD, Avrech OM, Colombero LT, Palermo GD, Rosenwaks Z. Effect of parental age on fertilization and pregnancy characteristics in couples treated by intracytoplasmic sperm injection. Hum Rep. 1998;13:334-8.

5. Paulson RJ, Milligan RC, Sokol RZ. The lack of influence of age on male fertility. Am J Obstet Gynecol. 2001;184:818-22.

6. Rolf C, Nieschlag E. Reproductive functions, fertility and genetic risks of ageing men. Exp Clin Endocrinol Diabetes. 2001;109:68-74.

7. Johson L, Abdo JG, Petty CS, Neaves WB. Effect of age on the composition of seminiferous tubular boundary tissue and on the volume of each component in humans. Fertil Steril. 1998;49:104551.

8. $\mathrm{Ng} \mathrm{KK}$, Donat R, Chan L, Lalak A, Di Pierro L, Handelsman DJ. Sperm output of older men. Hum Rep. 2004;19:1811-5.

9. Anderson AG, Jensen TK, Carlsen E, Jørgensen N, Andersson AM, Krarup T, et al. High frequency of sub-optimal semen quality in an unselected population of young men. Hum Rep. 2000;15:36672. 
10. Chianese C, Brilli S, Krausz C. Genomic changes in spermatozoa of the aging male. Adv Exp Med Biol. 2014;791:13-26.

11. Leutjens CM, Rolf C, Gassner P, Werny JE, Nieschlag E. Sperm aneuploidy rates in younger and older men. Hum Reprod. 2002;17:1826-32.

12. Asada H, Sueoka K, Hashiba T, Kuroshima M, Kobayashi N, Yoshimura Y. The effects of age and abnormal sperm count on the nondisjunction of spermatozoa. J Assis Reprod Genet. 2000;17:51-9.

13. World Health organization. Laboratory manual for the examination and processing of human semen. In: WHO, eds. WHO Manual. 5th ed. Geneva: WHO Press; 2010.

14. Wilkosz P, Greggains GD, Tanbo TG, Fedorcsak P. Female reproductive decline is determined by remaining ovarian reserve and age. PLoS One. 2014;9:e108343.

15. Ziebe S, Loft A, Petersen JH, Andersen AG, Lindenberg S, Petersen K, et al. Embryo quality and developmental potential is compromised by age. Acta Obstet Gynecol Scand. 2001;80:169-74.

16. Dew JE, Don RA, Hughes GJ, Johnson TC, Steigrad SJ. The influence of advanced age on the outcome of assisted reproduction. J Assist Reprod Genet. 1998;15:210-4.

17. Bar-Hava I, Orvieto R, Ferber A, Ashkenazi J, Dicker D, Ben-Rafael Z. Standard in vitro fertilization or intracytoplasmic sperm injection in advanced female age - what may be expected? Gynecol Endocrinol. 1999;13:93-7.

18. Qi ST, Liang LF, Xian YX, Liu JQ, Wang W. Arrested human embryos are more likely to have abnormal chromosomes than developing embryos from women of advanced maternal age. J Ovarian Res. 2014;7:65.

19. Ford WC, North K, Taylor H, Farrow A, Hull MG, Golding J. Increasing paternal age is associated with delayed conception in a large population of fertile couples: evidence for declining fecundity in older men. The ALSPAC Study Team (Avon Longitudinal Study of Pregnancy and Childhood). Hum Reprod. 2000;15:1703-8.

20. Klonoff-Cohen HS, Natarajan L. The effect of advancing paternal age on pregnancy and live birth rates in couples undergoing in vitro fertilization or gamete intrafallopian transfer. Am J Obstet Gynecol 2004;191:507-14.
21. de la Rochebrochard E, Thonneau P. Paternal age and maternal age are risk factors for miscarriage; results of a multicentre European study. Hum Reprod. 2002;17:1649-56.

22. Amann RP. The cycle of the seminiferous epithelium in humans: a need to revisit? J Androl. 2008;29:46987.

23. Kidd SA, Eskenazi B, Wyrobek AJ. Effects of male age on semen quality and fertility: a review of the literature. Fertil Steril. 2001;75:237-48.

24. Gallardo E, Simón C, Levy M, Guanes PP, Remohí J, Pellicer A. Effect of age on sperm fertility potential: oocyte donation as a model. Fertil Steril. 1996;66:260-4.

25. Levitas E, Lunenfeld E, Weisz N, Friger M, Potashnik G. Relationship between age and semen parameters in men with normal sperm concentration: analysis of 6022 semen samples. Andrologia. 2007;39:45-50.

26. Fisch H, Goluboff ET, Olson JH, Feldshuh J, Broder SJ, Barad DH. Semen analyses in 1283 men from the United States over a 25-year period: no decline in quality. Fertil Steril. 1996;65:1009-14.

27. Alfaraj SS, Yunus F. Advancing paternal age does not affect in vitro fertilization (IVF) outcomes in a Saudi population. Middle East Fertil Soc J Published online: 2014;1:1-5.

28. Ferreira R, Braga DP, Bonetti TC, Pasqualotto FF, Iaconelli A Jr, Borges E Jr. Negative influence of paternal age on clinical intracytoplasmic sperm injection cycle outcomes in oligozoospermic patients. Fertil Steril. 2010;93:1870-4

29. Mathieu C, Ecochard R, Bied V, Lornage J, Czyba JC. Cumulative conception rate following intrauterine artificial insemination with husband's spermatozoa: influence of husband's age. Hum Reprod. 1995;10:1090-7.

30. Zaragoza MV, Jacobs PA, James RS, Rogan P, Sherman S. Nondisjunction of human acrocentric chromosomes: studies of 432 trisomic fetuses and liveborns. Hum Genet. 1994;94:411-7.

31. Sartorelli EM, Mazzucatto LF, de Pina-Neto JM. Effect of paternal age on human sperm chromosomes. Fertil Steril. 2001;76:1119-23.

DOI: $10.18203 / 2320-1770$. ijrcog20150063

Cite this article as: Temel T, Akpak YK, Gün İ, Oral S, Sofuoğlu K. Impact of paternal age on intracytoplasmic sperm injection cycle results. Int J Reprod Contracept Obstet Gynecol 2015;4:622-8. 